\title{
Treatment of Vitamin D Deficiency in Cystic Fibrosis
}

\author{
Supavit Chesdachai, M.D. and Vin Tangpricha, M.D., Ph.D. \\ Division of Endocrinology, Metabolism and Lipids, Department of Medicine, Emory University \\ School of Medicine and the Atlanta VA Medical Center, Atlanta, GA, USA
}

\begin{abstract}
Vitamin D deficiency occurs frequently in patients with cystic fibrosis (CF). Vitamin D is important for optimal mineralization of bone and may be important for other comorbidities commonly occurring in patients with CF. Vitamin D deficiency in patients with CF can arise from various causes including pancreatic exocrine insufficiency, lack of outdoor activity, and alterations of vitamin D metabolism. Due to fat malabsorption stemming from pancreatic insufficiency, higher oral doses of vitamin D are necessary to correct and maintain optimal vitamin D status in patients with CF. Recent studies have demonstrated that higher vitamin D status is associated with better lung function and that vitamin $\mathrm{D}$ therapy may help recovery from pulmonary exacerbations of CF. The mechanisms by which vitamin D may exert its beneficial actions in CF are unclear but likely related to the role vitamin $\mathrm{D}$ has in modulating the adaptive and innate immune response. Large randomized clinical studies to evaluate the potential role of vitamin D as adjunctive therapy in $\mathrm{CF}$ that goes beyond bone are necessary.
\end{abstract}

\section{Background}

Cystic fibrosis (CF) is one of the most common lethal autosomal recessive diseases among Caucasians in the United States. There are about 30,000 patients with CF in United States and approximately 70,000 patients worldwide with an incidence of 1 out of every 3,200live births $(1,2)$. Cystic fibrosis results from a mutation in the cystic fibrosis transmembrane conductance regulator (CFTR) gene. There have been more than 1,600 mutations that have been described with the most common mutation of the CFTR being a deletion of the amino acid phenylalanine at the 508 position (F508del) (3). The CFTR is a chloride and bicarbonate membrane transporter located on the apical surface of epithelial cells. Mutations in the CFTR gene result in an absent or dysfunctional CFTR protein, leading to defects in chloride transport across the apical epithelial membrane(4). Defects in chloride transport

Corresponding Author: Vin Tangpricha, M.D., Ph.D., 101 Woodruff Circle NE, Atlanta GA 30322, Ph 404-727-7254, Fax 404-727-1300, vin.tangpricha@emory.edu.

Conflicts of Interest

The authors declare no conflicts of interest

The contents of this manuscript were also presented at the Vitamin D Workshop meeting in Delft, The Netherlands, April 21-24, 2015.

Publisher's Disclaimer: This is a PDF file of an unedited manuscript that has been accepted for publication. As a service to our customers we are providing this early version of the manuscript. The manuscript will undergo copyediting, typesetting, and review of the resulting proof before it is published in its final citable form. Please note that during the production process errors may be discovered which could affect the content, and all legal disclaimers that apply to the journal pertain. 
result in dysfunction in fluid transport on epithelial membranes and thickened secretions lining epithelial surfaces, including the lung, pancreas, and colon.

The major co-morbidity and cause for mortality in patients with CF is chronic lung infection resulting in progressive respiratory decline. The CFTR dysfunction causes mucous stasis resulting in a susceptible environment for bacterial colonization for pathogenic bacteria such as Pseudomonas aeruginosa, chronic lung infection by other pathogenic bacteria, and chronic lung inflammation which can progress to end stage lung disease (4).In the pancreas of patients with CF, stasis of mucous, reduction of pancreatic fluid flow and increased concentration of protein results in pancreatic fibrosis, destruction and eventual insufficiency, leading to malabsorption of fat and fat-soluble vitamins, including vitamin $\mathrm{D}(5,6)$. Other endocrine abnormalities can occur in patients with $\mathrm{CF}(7)$. Cystic fibrosis related diabetes (CFRD), delayed puberty and impaired fertility are also commonly occurring endocrine comorbidities in patients with $\mathrm{CF}(7)$.

\section{Vitamin D Insufficiency and Deficiency in CF}

The prevalence of vitamin D insufficiency (serum 25-hydroxyvitamin $\mathrm{D}(25(\mathrm{OH}) \mathrm{D}<30$ $\mathrm{ng} / \mathrm{mL}$ ) and deficiency (serum $25(\mathrm{OH}) \mathrm{D}<20 \mathrm{ng} / \mathrm{mL}$ ) in CF is high. Recent studies demonstrate that prevalence of vitamin D insufficiency in the CF population is up to $90 \%$ (8, 9). The etiologies of vitamin D insufficiency and deficiency are multifactorial in patients with CF. Pancreatic insufficiency is one major causes for vitamin D insufficiency; however, there other factors including reduced sunlight exposure, reduction of body fat and vitamin $\mathrm{D}$ binding protein, and impairment of hepatic hydroxylation of vitamin $\mathrm{D}(10)$. As in the general population, the serum 25-hydroxyvitamin $\mathrm{D}(25(\mathrm{OH}) \mathrm{D})$ is used to determine vitamin D status. The Cystic Fibrosis Foundation recommends that the serum 25(OH)D concentration be checked annually preferably at the end of winter and should be maintained above $30 \mathrm{ng} / \mathrm{mL}$ (75nmol/L)year round(11).

\section{Potential Role of Vitamin D in CF}

\section{Skeletal Health}

Vitamin D plays a crucial role in maintaining proper bone mineralization in both the healthy and CF population. Sub-optimal concentrations of serum 25(OH)D results in secondary hyperparathyroidism potentially leading to a decrease in bone mineralization and eventually increasing the risk of osteopenia, osteoporosis and fracture (12). Early studies found that vitamin $\mathrm{D}$ deficiency $(25(\mathrm{OH}) \mathrm{D}<10 \mathrm{ng} / \mathrm{mL})$ in adults with advanced $\mathrm{CF}$ was associated with lower bone mineral density at the hip and spine compared to adults with CF with higher serum 25(OH)D concentrations(13). Studies in children with CF have demonstrated that serum $25(\mathrm{OH}) \mathrm{D}$ positively correlated with Z-score at the femoral neck and lumbar spine(14, $15)$.

According to the 2013 CF Foundation patient registry, 21\% of young adults with CF have osteopenia(16). Moreover, a systematic review and meta-analysis from 12 studies in the $\mathrm{CF}$ population have shown that the prevalence of osteopenia, osteoporosis vertebral and nonvertebra fractures are $38 \%$ and $23.5 \%, 14 \%$ and $19.7 \%$ respectively(17).Although vitamin 
D deficiency is likely a major contributor to $\mathrm{CF}$ bone disease, there are many factors that contribute to bone disease in CF patients such as malnutrition, sex hormone deficiency, glucocorticoid usage and chronic inflammation (18).

\section{Lung Function}

Vitamin D may have a role in preserving lung function in the CF population(19). According to the Third National Health and Nutrition Examination Survey (NHANES III), there was a positive correlation between vitamin D status and lung function as assessed by the forced expiratory volume in 1 second (FEV1) and forced vital capacity (FVC) (20). One retrospective cohort found that vitamin D status was positively associated with FEV1 in patients with $\mathrm{CF}(8)$. Other studies in $\mathrm{CF}$ populations have demonstrated that higher vitamin D status has been associated with better lung function and lower rates of pulmonary exacerbation $(8,21-23)$. The potential mechanisms by which vitamin $\mathrm{D}$ may preserve lung function based on studies in cystic fibrosis and other chronic lung disease include improved airway remodeling in response to injury, decreased airway inflammation, and decreased airway bacterial colonization (19).

\section{Pulmonary Exacerbations and Infections}

Patients with $\mathrm{CF}$ are at increased risk for lung infections and frequently require hospitalization for treatment with intravenous antibiotics. Vitamin $\mathrm{D}$ has been established to enhance the innate immune system by up-regulating antimicrobial peptides such as human cathelicidin (hCAP18 or its cleaved protein LL-37)(24). Invading microorganisms can bind to toll-like receptors on alveolar macrophages which result in up-regulation of the 1ahydroxylaseand increased production of the active form of vitamin $\mathrm{D}\left(1,25(\mathrm{OH})_{2} \mathrm{D}\right)$ and the vitamin D receptor $(\mathrm{VDR})(25)$. The locally produced $1,25(\mathrm{OH})_{2} \mathrm{D}$ can induce expression of cathelicidin by macrophages and monocytes to clear the infection by the invading microorganisms $(24,25)$.Specific to $\mathrm{CF}$, locally produced $1,25(\mathrm{OH})_{2} \mathrm{D}$ can potentially enhance airway concentrations ofLL-37 to decrease colonization of airway pathogens such as Pseudomonas aeruginosa and Bordetellabronchiseptica(26). Vitamin D can also down regulate pro-inflammatory cytokine in macrophages and may also reduce the inflammation in the CF airway(27).Vitamin D may also have beneficial effects on induction of reactive nitrogen and oxygen intermediates and induction of autophagy to help clear infections (28).

High dose vitamin $\mathrm{D}$ given during the time of pulmonary exacerbation may improve outcomes in adults with $\mathrm{CF}$ who are hospitalized with a pulmonary exacerbation. In a randomized controlled double blind placebo controlled trial, 30 adults with CF hospitalized with a pulmonary exacerbation were randomized to receive a one-time oral dose of 250,000 IU cholecalciferol (vitamin $\mathrm{D}_{3}$ ) or placebo. Subjects who received the vitamin $\mathrm{D}$ had better antibiotic therapy-free days, hospital-free days and 1 year survival compared to placebo group(29).In addition, inflammatory markers including tumor necrosis factor-a (TNF-a) and interleukin-6 (IL-6) were significantly reduced in high dose vitamin D group $(29,30)$. This pilot clinical study suggests that high dose vitamin D in patients with CF may be a beneficial adjunctive therapy during acute respiratory infection. These results are currently being confirmed with a follow-up larger multi-center study funded by the $\mathrm{CF}$ Foundation(31). 


\section{Treatment of Vitamin D Deficiency in CF}

Previous guidelines on vitamin D for patients with CF recommended ergocalciferol (vitamin $\mathrm{D}_{2}$ ) for treatment of vitamin D deficiency.(18). However, only $8 \%$ of patients with CF achieved optimal vitamin D using these former guidelines(32). Despite doses of ergocalciferol that were higher than what was recommended by the previous guidelines, the success rate of treatment with ergocalciferol was still inadequate(33). Moreover, the absorption of ergocalciferol may be sub-optimal in patients with CF due to the oil based vehicle of the commercially available capsule of ergocalciferol(11, 34, 35). In contrast, studies have indicated success with the use of cholecalciferol in improving vitamin D status in patients with $\mathrm{CF}(23)$. In addition, a prospective randomized study in adults with $\mathrm{CF}$ demonstrated that cholecalciferol was superior to ergocalciferol in raising serum $25(\mathrm{OH}) \mathrm{D}$ concentrations (36). Therefore, the Cystic Fibrosis Foundation recommends that all CF patients with vitamin $\mathrm{D}$ deficiency should be preferably treated with cholecalciferol rather than ergocalciferol(11).

Vitamin D can be prescribed as a daily or weekly supplement in patients with CF to prevent and treat vitamin D deficiency and insufficiency(11). The dose of vitamin D supplementation depends on the age and vitamin $\mathrm{D}$ status. For both adults and children with CF should be initially treated with vitamin $\mathrm{D}_{3} 800-2,000$ IU/day and the dose should be titrated until a serum $25(\mathrm{OH}) \mathrm{D}$ concentration is greater than $30 \mathrm{ng} / \mathrm{mL}$, with maximum dose of 4,000 IU/day in children and 10,000 IU/day in adults(11).In general, vitamin D from diet is insufficient to maintain optimal vitamin D status in CF. Sunlight exposure is another important source of vitamin D. A retrospective study in the CF population shows that there is seasonal variation in serum $25(\mathrm{OH}) \mathrm{D}$ in high UV exposure months (May to October) compared to low UV exposure months (November to April) (37). Sun exposure and outdoor activities should be encouraged in CF patients as well.

\section{Conclusions}

Vitamin D insufficiency and deficiency are very common in patients with CF due to multiple factors, including pancreatic exocrine insufficiency. Vitamin D deficiency is one of the major contributors to increased risk of fractures, osteopenia and osteoporosis in CF patients.

Moreover, preliminary data suggest that vitamin D deficiency may contribute to the decline in lung function associated with CF. Vitamin D therapy may enhance anti-microbial peptide production and decrease pro-inflammatory cytokines which could result in improved clinical outcomes. Preventing vitamin D deficiency in patients with CF seems prudent until the results from large randomized controlled studies in CF are available.

\section{Acknowledgments}

The work presented in this manuscript has been funded in part by a grant from the CF Foundation.

\section{References}

1. Strausbaugh SD, Davis PB. Cystic fibrosis: a review of epidemiology and pathobiology. Clinics in chest medicine. 2007; 28(2):279-88. [PubMed: 17467547] 
2. Salvatore D, Buzzetti R, Baldo E, Forneris MP, Lucidi V, Manunza D, et al. An overview of international literature from cystic fibrosis registries. Part 3. Disease incidence, genotype/phenotype correlation, microbiology, pregnancy, clinical complications, lung transplantation, and miscellanea. Journal of cystic fibrosis : official journal of the European Cystic Fibrosis Society. 2011; 10(2):7185. [PubMed: 21257352]

3. Cutting GR. Cystic fibrosis genetics: from molecular understanding to clinical application. Nature reviews Genetics. 2015; 16(1):45-56.

4. Collawn JF, Matalon S. CFTR and lung homeostasis. American journal of physiology Lung cellular and molecular physiology. 2014; 307(12):L917-23. [PubMed: 25381027]

5. O’Sullivan BP, Freedman SD. Cystic fibrosis. Lancet. 2009; 373(9678):1891-904. [PubMed: 19403164]

6. Couper RT, Corey M, Moore DJ, Fisher LJ, Forstner GG, Durie PR. Decline of exocrine pancreatic function in cystic fibrosis patients with pancreatic sufficiency. Pediatric research. 1992; 32(2):17982. [PubMed: 1508606]

7. Siwamogsatham O, Alvarez JA, Tangpricha V. Diagnosis and treatment of endocrine comorbidities in patients with cystic fibrosis. Current opinion in endocrinology, diabetes, and obesity. 2014; 21(5): 422-9.

8. Wolfenden LL, Judd SE, Shah R, Sanyal R, Ziegler TR, Tangpricha V. Vitamin D and bone health in adults with cystic fibrosis. Clinical endocrinology. 2008; 69(3):374-81. [PubMed: 18284636]

9. Rovner AJ, Stallings VA, Schall JI, Leonard MB, Zemel BS. Vitamin D insufficiency in children, adolescents, and young adults with cystic fibrosis despite routine oral supplementation. The American journal of clinical nutrition. 2007; 86(6):1694-9. [PubMed: 18065588]

10. Hall WB, Sparks AA, Aris RM. Vitamin d deficiency in cystic fibrosis. International journal of endocrinology. 2010; 2010:218691. [PubMed: 20148079]

11. Tangpricha V, Kelly A, Stephenson A, Maguiness K, Enders J, Robinson KA, et al. An update on the screening, diagnosis, management, and treatment of vitamin D deficiency in individuals with cystic fibrosis: evidence-based recommendations from the Cystic Fibrosis Foundation. The Journal of clinical endocrinology and metabolism. 2012; 97(4):1082-93. [PubMed: 22399505]

12. Grober U, Spitz J, Reichrath J, Kisters K, Holick MF. Vitamin D: Update 2013: From rickets prophylaxis to general preventive healthcare. Dermato-endocrinology. 2013; 5(3):331-47. [PubMed: 24516687]

13. Donovan DS Jr, Papadopoulos A, Staron RB, Addesso V, Schulman L, McGregor C, et al. Bone mass and vitamin D deficiency in adults with advanced cystic fibrosis lung disease. American journal of respiratory and critical care medicine. 1998; 157(6 Pt 1):1892-9. [PubMed: 9620924]

14. Cemlyn-Jones J, Gamboa F, Teixeira L, Bernardo J, Robalo Cordeiro C. Sarcoidosis: a less common presentation. Revista portuguesa de pneumologia. 2009; 15(3):543-52. [PubMed: 19401802]

15. Douros K, Loukou I, Nicolaidou P, Tzonou A, Doudounakis S. Bone mass density and associated factors in cystic fibrosis patients of young age. Journal of paediatrics and child health. 2008; 44(12):681-5. [PubMed: 19077069]

16. Cystic Fibrosis Foundation Patient Registry 2013 Annual Data Report to the Center Directors. Bethesda, Maryland: Cystic Fibrosis Foundation; 2013.

17. Paccou J, Zeboulon N, Combescure C, Gossec L, Cortet B. The prevalence of osteoporosis, osteopenia, and fractures among adults with cystic fibrosis: a systematic literature review with meta-analysis. Calcified tissue international. 2010; 86(1):1-7. [PubMed: 19949942]

18. Aris RM, Merkel PA, Bachrach LK, Borowitz DS, Boyle MP, Elkin SL, et al. Guide to bone health and disease in cystic fibrosis. The Journal of clinical endocrinology and metabolism. 2005; 90(3): 1888-96. [PubMed: 15613415]

19. Finklea JD, Grossmann RE, Tangpricha V. Vitamin D and chronic lung disease: a review of molecular mechanisms and clinical studies. Advances in nutrition (Bethesda, Md). 2011; 2(3): 244-53.

20. Black PN, Scragg R. Relationship between serum 25-hydroxyvitamin d and pulmonary function in the third national health and nutrition examination survey. Chest. 2005; 128(6):3792-8. [PubMed: 16354847] 
21. Vanstone MB, Egan ME, Zhang JH, Carpenter TO. Association between serum 25-hydroxyvitamin D level and pulmonary exacerbations in cystic fibrosis. Pediatric pulmonology. 2015; 50(5):441-6. [PubMed: 25657016]

22. Sexauer WP, Hadeh A, Ohman-Strickland PA, Zanni RL, Varlotta L, Holsclaw D, et al. Vitamin D deficiency is associated with pulmonary dysfunction in cystic fibrosis. Journal of cystic fibrosis : official journal of the European Cystic Fibrosis Society. 2015

23. Stephenson A, Brotherwood M, Robert R, Atenafu E, Corey M, Tullis E. Cholecalciferol significantly increases 25 -hydroxyvitamin D concentrations in adults with cystic fibrosis. The American journal of clinical nutrition. 2007; 85(5):1307-11. [PubMed: 17490967]

24. Liu PT, Stenger S, Li H, Wenzel L, Tan BH, Krutzik SR, et al. Toll-like receptor triggering of a vitamin D-mediated human antimicrobial response. Science (New York, NY). 2006; 311(5768): 1770-3.

25. Hewison M. Vitamin D and the intracrinology of innate immunity. Molecular and cellular endocrinology. 2010; 321(2):103-11. [PubMed: 20156523]

26. Yim S, Dhawan P, Ragunath C, Christakos S, Diamond G. Induction of cathelicidin in normal and CF bronchial epithelial cells by 1,25-dihydroxyvitamin $\mathrm{D}(3)$. Journal of cystic fibrosis : official journal of the European Cystic Fibrosis Society. 2007; 6(6):403-10. [PubMed: 17467345]

27. Herscovitch K, Dauletbaev N, Lands LC. Vitamin D as an anti-microbial and anti-inflammatory therapy for Cystic Fibrosis. Paediatric respiratory reviews. 2014; 15(2):154-62. [PubMed: 24332502]

28. Korf H, Decallonne B, Mathieu C. Vitamin D for infections. Current opinion in endocrinology, diabetes, and obesity. 2014; 21(6):431-6.

29. Grossmann RE, Zughaier SM, Kumari M, Seydafkan S, Lyles RH, Liu S, et al. Pilot study of vitamin D supplementation in adults with cystic fibrosis pulmonary exacerbation: A randomized, controlled trial. Dermato-endocrinology. 2012; 4(2):191-7. [PubMed: 22928076]

30. Grossmann RE, Zughaier SM, Liu S, Lyles RH, Tangpricha V. Impact of vitamin D supplementation on markers of inflammation in adults with cystic fibrosis hospitalized for a pulmonary exacerbation. European journal of clinical nutrition. 2012; 66(9):1072-4. [PubMed: 22805498]

31. Lee MJAJ, Smith EM, Killilea DW, Chmiel J, Joseph P, Grossmann RE, Gaggar A, Ziegler TR, Tangpricha V. Changes in Mineral Micronutrient Status During and After Pulmonary Exacerbation in Adults with Cystic Fibrosis. Nutrition in Clinical Practice. 2015; 30 (4):1-6.

32. Boyle MP, Noschese ML, Watts SL, Davis ME, Stenner SE, Lechtzin N. Failure of high-dose ergocalciferol to correct vitamin D deficiency in adults with cystic fibrosis. American journal of respiratory and critical care medicine. 2005; 172(2):212-7. [PubMed: 15860755]

33. Green D, Carson K, Leonard A, Davis JE, Rosenstein B, Zeitlin P, et al. Current treatment recommendations for correcting vitamin $\mathrm{D}$ deficiency in pediatric patients with cystic fibrosis are inadequate. The Journal of pediatrics. 2008; 153(4):554-9. [PubMed: 18589445]

34. Lark RK, Lester GE, Ontjes DA, Blackwood AD, Hollis BW, Hensler MM, et al. Diminished and erratic absorption of ergocalciferol in adult cystic fibrosis patients. The American journal of clinical nutrition. 2001; 73(3):602-6. [PubMed: 11237938]

35. Grossmann RE, Tangpricha V. Evaluation of vehicle substances on vitamin D bioavailability: a systematic review. Molecular nutrition \& food research. 2010; 54(8):1055-61. [PubMed: 20425758]

36. Khazai NB, Judd SE, Jeng L, Wolfenden LL, Stecenko A, Ziegler TR, et al. Treatment and prevention of vitamin D insufficiency in cystic fibrosis patients: comparative efficacy of ergocalciferol, cholecalciferol, and UV light. The Journal of clinical endocrinology and metabolism. 2009; 94(6):2037-43. [PubMed: 19336509]

37. Robberecht E, Vandewalle S, Wehlou C, Kaufman JM, De Schepper J. Sunlight is an important determinant of vitamin D serum concentrations in cystic fibrosis. European journal of clinical nutrition. 2011; 65(5):574-9. [PubMed: 21245888] 


\section{Highlights}

- Vitamin D insufficiency is common in patients with cystic fibrosis.

- Vitamin D status is important for bone health, lung and immune function in patients with cystic fibrosis.

- $\quad$ Treatment of vitamin D insufficiency in patients with cystic fibrosis requires high dose cholecalciferol or ergocalciferol.

- $\quad$ Randomized, double blind, placebo controlled, large scale clinical trials are underway to evaluate the role of vitamin $\mathrm{D}$ as an adjunctive treatment in patients with cystic fibrosis. 